\title{
¿COMUNICAS, LUEGO EXISTES? UNA CRÍTICA A LA IDEOLOGÍA DE LA COMUNICACIÓN
}

\author{
YOU COMMUNICATE, THEREFORE EXIST? A CRITIQUE TO THE \\ IDEOLOGY OF THE COMMUNICATION
}

\author{
Belén Blesa Aledo ${ }^{1}$ \\ Universidad Católica San Antonio (España)
}

Recibido: 12-03-2013

Aceptado: 16-07-2013

\begin{abstract}
Resumen: Este artículo se aproxima al impacto que las diversas posibilidades y usos que ofrecen los medios tecnológicos de la comunicación, insertos en el marco de una cultura de consumo, tienen respecto a determinadas categorías existenciales y éticas. Comunicas, luego existes aparece como una nueva consigna filosófica que reabre con fuerza preguntas como ¿qué significa estar disponible? ¿Qué relación mantenemos con el tiempo? o ¿qué paradojas plantea a nuestra libertad la sobreabundancia de posibilidades?. En segundo lugar, y a partir de los riesgos y paradojas identificados, se sugiere una toma de conciencia de los límites propios apelando a una vuelta a lo concreto, desde el cuerpo, la reflexión y la serenidad.
\end{abstract}

Palabras-clave: Comunicación, consumo, disponibilidad, libertad, cuerpo, serenidad.

\begin{abstract}
This article deals with the impact that, in relation with certain existential and ethical categories, has the diverse uses and possibilities that new technologies applied to communication and mass media grant to us today. "You communicate, so you exist", as it goes, appears as a new philosophical motto that opens new questions like: What it means to be available?. What kind of relation we develop with the concept of time? What kind of paradoxes confront our freedom when facing an overabundant of possibilities from where
\end{abstract}

[1] (bblesa@ucam.edu) Profesora de Sociedad, familia y escuela en los Grados de Educación Infantil y Primaria en la Universidad Católica de San Antonio.

Otros artículos publicados:

"La identidad personal y el cuerpo en Gabriel Marcel”. En Anuario Filosófico. Vol. 43, n 99, 2010, pp. 511-536

"La identidad personal en Gabriel Marcel y su proyección sociológica". En Pensamiento. Revista de investigación e información filosófica. Vol. 68, n 257, 2012, pp. 427-443

"El lugar del silencio en la era de la comunicación" En Sphera Publica. N 12. 2012, pp.255-268. 
to choose? In the second place, and emerging from the risks and paradoxes previously identified in this article, it is suggested a new awareness in relation to the limits of our experience, advising a new return to the concrete from the body outward, meditation and serenity.

Key-words: Communication, comsuption, availability, freedom, body, serenity.

\section{Introducción}

Hacer una aproximación analítica del contexto y el momento en el que uno está inmerso es una empresa complicada en varios sentidos. Por un lado nos sitúa frente a la dificultad de distanciarnos para mirar con cierta perspectiva, por otro, siempre se corre el riesgo de asomarse al presente desde categorías del pasado que no permiten entender de manera ajustada cuál es el sentido de los acontecimientos. Disciplinas como la filosofía o las ciencias sociales se encuentran ante esta encrucijada intelectual que las llena de sentido.

Este texto se asoma a las inquietudes y problemáticas que presenta la comunicación bajo sus nuevos usos y posibilidades en la Sociedad Red ${ }^{2}$. Partimos del hecho insoslayable de que desde la segunda mitad del siglo XX se han venido produciendo una serie de transformaciones a nivel tecnológico, social, político, económico, que han creado unas nuevas condiciones de vida y que autores como Gilles Lipovetsky, han venido a catalogar como un cambio cultural bajo la tutela de un mercado que todo lo abarca ${ }^{3}$. En el seno de este cambio cabe detenerse en el gran impacto que ha supuesto el desarrollo tecnológico y las nuevas posibilidades y usos que ha generado desde el punto de vista de las relaciones sociales y la comunicación. Estas posibilidades, en aumento de manera vertiginosa, no deben llevarnos a ciegas hacia un optimismo tecnológico que no sepa medir y valorar adecuadamente algunas de las paradojas que tal desarrollo arrastra consigo, o identificar nuevos mitos bajo la apariencia de novedad con gran poder de fascinación. Una de las creencias en las que arraigó con fuerza este optimismo consistió en considerar que la democratización en el acceso a la información traería consigo una mayor

[2] Para Manuel Castells las redes, favorecidas por el desarrollo de la tecnología de la información y de internet son la estructura organizativa propia de nuestra época. De hecho, afirma: "internet es la sociedad, una sociedad cuya estructura social está construida en torno a redes de información a partir de la tecnología de información microelectrónica estructurada en Internet (...) Internet es la base material de nuestras vidas y de nuestras formas de relación, de trabajo y de comunicación. Lo que hace Internet es procesar la virtualidad y transformarla en nuestra realidad, constituyendo la sociedad red, que es la sociedad en que vivimos". En Castells, M. Internet y la Sociedad Red. Lección inaugural del programa de doctorado sobre la Sociedad de la información y el conocimiento en la UOC 2001.

[3] Lipovetsky, G.: La cultura mundo. Barcelona: Anagrama, 2012, p. 16, 17.

THÉMATA. Revista de Filosofía, Nº 49 enero-junio (2014) pp.: 85-103 doi: 10.12795/themata.2014.i49.05 
igualdad en el conocimiento y una mayor igualdad social ${ }^{4}$.

Una de las paradojas actuales apunta a que el más fácil y mayor acceso a la información, el mayor y más pormenorizado conocimiento relativo a acontecimientos, personas, lugares, etc., nuestra mayor disponibilidad para estar conectados, también arrastran una sensación creciente de fragilidad, desorientación y confusión sobre el conjunto del mundo y de las relaciones, hasta el punto de que se podría hablar de un riesgo de carácter estructural y crónico ${ }^{5}$.

La hipótesis de partida que planteamos es que la vorágine actual por estar comunicados no implica necesariamente una mejor ni más fecunda relación entre las personas, sino que se puede interpretar también como una práctica de consumo y como una expresión de individualismo.

Si en la segunda mitad del siglo XX, y en Europa de un modo especial a raíz de la activación económica producida en los años 50, y a la luz de la revolución de mayo del 68, entre otros acontecimientos, adquiere énfasis un consumo de carácter lúdico-libidinal asociado a productos que enfatizan el cuerpo y los placeres corporales ${ }^{6}$, estas últimas décadas, sin perder de vista el lugar clave que sigue ocupando el cuerpo en los reclamos del consumo, ha virado hacia un consumo centrado en la comunicación entendida principalmente como entretenimiento. Esta práctica está asociada a la aparición de productos tecnológicos y usos que éstos hacen posibles como el de redes sociales. En este sentido, en España, por ejemplo, de 2009 a 2012 se ha producido un claro incremento del consumo de redes entre la población de internautas con edades comprendidas entre 18 y 55 años, pasando de un 51\% a un 79\%, y las perspectivas van en aumento. Los usos principales a los que se destinan son: ser espectador de lo que otros internautas exponen, intercambiar mensajes con los contactos de carácter privado y público, y queda en un segundo lugar la elaboración de contenidos?

Nuestro interés no es desmantelar la cultura de consumo actual vinculada a la comunicación, sino indagar cómo nos afecta y en qué sentido nos vuelve vulnerables, sin detrimento, por supuesto, de las nuevas posibilidades y configuraciones de la vida y del conocimiento, entendidas en positivo, a que está dando lugar. Cabe considerar la enorme utilidad que presentan las redes

[4] Fernández Enguita, M. La institución escolar en la Sociedad de la información y el conocimiento, en Feito R. (coord.) Sociología de la educación secundaria. Barcelona: Graó, 2010.

[5] Lipovetsky, Op. Cit. P. 19.

[6] Véase Le Breton, Sociología del cuerpo y también Houellebecq, M. que en Las partículas elementales desmitifica muchas de las promesas esperadas con esta apertura y liberación del placer que dan más bien lugar a un ahogo del deseo, encarnando en los personajes la dureza de este optimismo libertario.

[7] IV estudio anual de redes sociales. Enero 2013. Estudio realizado por IAB y ELOGIA. Puede consultarse en http://www.iabspain.net/wp-content/uploads/downloads/2013/01/IV-estudio-anualRRSS_reducida.pdf

THÉMATA. Revista de Filosofía, № 49 enero-junio (2014) pp.: 85-103 doi: 10.12795/themata.2014.i49.05 
sociales tanto en su uso de carácter privado como público, institucional, empresarial y profesional, y el cambio cualitativo que han supuesto. Así, redes como Facebook o twitter, pueden constituir un instrumento de libertad y autonomía porque es difícil controlar lo que hace la gente en red, presentan mayores posibilidades de sociabilidad ${ }^{8}$, de eliminación de barreras espacio-temporales y culturales, de generación de conocimiento y de intercambio. Han creado nuevos horizontes en la forma de entender y hacer política, favoreciendo un cuestionamiento de las jerarquías de poder y abriendo la puerta a una participación más real, por tanto, están creando nuevas vías para una democracia real; además de menor coste económico, rapidez y simultaneidad en la comunicación, mayor adaptabilidad y flexibilidad, poder de convocatoria y movilización como se ha podido ver en el caso de la primavera árabe. Sin embargo, el análisis de todos estos aspectos sería motivo de otro trabajo con consistencia propia.

Frente a una actitud eufórica y/o neutral ante las posibilidades de comunicación que presentan las tecnologías, sus aplicaciones y usos, ofrecemos una perspectiva cauta centrada en los riesgos que implican aspectos existenciales y éticos. En lugar de posibilidades vamos a enfrentar vulnerabilidades.

Partimos, para ello, de uno de los postulados actuales que tiene que ver con el ideal de individuo comunicante y disponible a tiempo completo, que encarna los valores de la eficacia, la socialidad y el conocimiento de un mundo que resulta ser un pañuelo. Y una de las ideologías que sirven de base a este concepto del individuo contemporáneo es el nuevo imperativo: comunicas luego existes, entendiendo por tal el formar parte de unas redes expuestas al ojo que todo lo ve. El leit motiv, especialmente para las jóvenes generaciones, es ser parte activa de este entramado virtual, convertido en el escenario global donde se tejen gran parte de la vida y del conocimiento.

\footnotetext{
"Había aprendido a hablar, por lo que se ve, ante los otros, no mucho él consigo mismo" Cicerón
}

\section{Comunicas, luego existes}

En un mundo caracterizado por el furor de las comunicaciones, -así podemos citar que en lo relativo al uso de redes sociales, Facebook supera ya los 800 millones de usuarios en el mundo, Twitter supera los 200 millones, y Tuenti se sitúa en torno a los 12 millones, por citar algunas, y otras datos como que se han llegado a contabilizar 27.000 millones de whatsApp en un día-, y donde las posibilidades que ofrece la tecnología al respecto resultan abrumadoras, el afán desmesurado por decir, por mostrarse, bajo

[8] Son algunos de los aspectos que destacan Castells y Subirats en Hombres y mujeres, ¿̇un amor imposible? Sin embargo, a lo largo del texto veremos cómo existen argumentos contrapuestos o menos optimistas, defendidos por autores como David Le Breton.

THÉMATA. Revista de Filosofía, $\mathrm{N}^{\circ} 49$ enero-junio (2014) pp.: 85-103 doi: 10.12795/themata.2014.i49.05 
la versión de palabras, imágenes, etiquetas o vídeos, se convierte en una de las más destacadas ideologías actuales. La nueva consigna filosófica es: "comunicas, luego existes". La categoría de ideología aplicada a la comunicación hace referencia al optimismo tecnológico derivado de una fascinación, más que de una actitud crítica, que convierte a la comunicación más en una tendencia y una posibilidad amplificada que ofrece la tecnología que en un acontecimiento con medida y uso humano, en un decir por decir que manifiesta la superioridad en el estatus de la insignificancia del decir por encima del silencio o la prudencia.

No toda forma de intercambio supone una comunicación, no toda relación que etiquetamos con el término amigo supone una amistad en el sentido ético que presenta este concepto y un largo etc. de términos y realidades que han acabado relacionándose de una manera laxa, o que se han absolutizado en función de su posibilidad más novedosa. Al remarcar esta posibilidad de caer en confusión no pretendemos situarnos en el enfrentamiento entre dos formas de entender la cultura y todo el entramado de relaciones y concepciones del mundo que ésta lleva consigo. No se trata de enfrentar una concepción de la cultura culta y profunda que representa el pasado inmediato, a una concepción de la cultura superficial propia del presente, situándose en la primera los verdaderos fundamentos de la comunicación o la posibilidad de una comunicación auténtica, y en la segunda no más que un sucedáneo de la misma. Esta contraposición resulta artificiosa y sesgada. Ante esta polémica son enormemente esclarecedoras las siguientes preguntas:

"¿Cómo no asegurarse de que las censuras al videojuego, el asco al marketing, la abominación de las marcas no sean un discurso de clase? Clase social, cultural, élites desesperadas de intelectuales con problemas de adaptación (...) ¿Cómo será posible seguir valorando de la misma manera las obras de la contemporaneidad si los modos de vivir, de gozar y de saber han sido trastornados por las nuevas tecnologías, los mass media (...)? ? ${ }^{9}$

La contextualización del problema que presentamos no se inscribe pues, en una cuestión de profundidad o superficialidad culturales, a menudo fuente de estrechos análisis y de privilegios adquiridos ${ }^{10}$, sino que se inserta más bien en una cuestión antropológica y ética que circunda al fenómeno de la comunicación y que se plantea en el seno de la sociedad red: ¿cómo afectará a los individuos el hecho de ser usuarios casi a tiempo completo en un contexto técnico-comunicativo en el que las categorías éticas y existenciales no son evidentes, y donde la educación presenta unos límites claros, ya que ni la familia ni la escuela, agentes encargados tradicionalmente de la educación ética, son

[9] Verdú, V. Tú y yo objetos de lujo, Barcelona, Debolsillo, 2005. Pp. 14-15.

[10] Al contrario de esa estrechez, Gilles Deleuze cuestiona que la superficialidad tenga que ser identificada con falta de calado y no más bien con dilatada dimensión. Verdú en op. Cit. se hace eco de este comentario de Deleuze que aparece en Lógica del sentido.

THÉMATA. Revista de Filosofía, № 49 enero-junio (2014) pp.: 85-103

doi: 10.12795/themata.2014.i49.05 
muchas veces entornos competentes para formar en este sentido, por el desconocimiento de los propios medios y lo que en ellos sucede? ¿Son capaces los usuarios, especialmente si pensamos en niños y adolescentes, de regular o de establecer en sus prácticas comunicativas en red los límites éticos de la comunicación? ¿Qué efectos tendrá desde un punto de vista antropológico poder convivir con identidades diferentes, dar tratamiento público a asuntos privados, romper una relación a golpe de click, seguir las sugerencias de una aplicación de móvil para salir de una ruptura amorosa ${ }^{11}$ ?

En nuestra socialización, especialmente durante la infancia, vamos interiorizando toda una serie de normas, formas de expresión, significados sociales y culturales, de carácter manifiesto y también latente. Éstos últimos resultan de vital importancia en nuestra vida social, y están implicados de una manera directa en la creación de sentido. El lenguaje corporal, incluyendo toda la manifestación de los afectos y también su regulación, se inscribe a menudo en esta socialización latente. La adquisición de estos contenidos se comienza a adquirir con la familia y la escuela. Pero la comunicación en internet, nos abre a una nueva realidad, y aunque no incite, sí que facilita sobremanera prácticas dudosas como la ocultación o suplantación de la identidad, de las intenciones ${ }^{12}$, etc., porque no hace presente un elemento clave en la comunicación como es el cuerpo, especialmente el rostro que es la parte del cuerpo que acumula la mayor especificidad emocional. Nuestra presencia corporal no sólo lleva consigo valores de tipo estético, sino también ético, estando además ambos muy relacionados. La ausencia del cuerpo puede realizar un desplazamiento de aspectos éticos como la responsabilidad o restar intensidad y significatividad a otros como el compromiso, el perdón. Esto no significa que sin la presencia del cuerpo la comunicación elimine, sin más, esta dimensión ética que el cuerpo no siempre es capaz de garantizar, pero sí que nos sumerge en una distinta dimensión sobre la que se requiere indagar. Nos preguntamos entonces en qué lugar nos deja el hecho de narrar en imágenes y/o palabras cualquier cosa. ¿Es posible decir cualquier experiencia? ¿Es deseable?, ¿nos favorece que porque algo se pueda decir, por fuerza, en el sentido de por tendencia o moda, haya que decirlo?

[11] Es el caso de aplicaciones que siguen el proceso de la ruptura en las distintas fases. Así, en una primera, Kill Switch (Android) elimina cualquier rastro del ex de Facebook, o E-lover blocker (IOS) que congela el número de teléfono del ex y avisa de las consecuencias de contactarle de nuevo. En una segunda ofrecen técnicas de meditación para evitar hacer juicios del ex, Mindfulness app (Android e IOS) y en una tercera ofrecen nuevas posibilidades de ligue.

[12] "Internet es un mundo de máscaras, que suprime todas las responsabilidades ligadas a las coerciones de la identidad. No tener que rendir cuentas, no tener ya miedo de no poder mirarse de frente es la fuente de la fascinación de los foros, de los chats y otros lugares de discusión de la red. Palabras sin rostro, sin posibilidad de verificación, que autorizan la multiplicación de las identidades en una suerte de carnaval donde nadie sabe nunca a quién se dirige en realidad". Le Breton D., Breton, P. El silencio y la palabra contra los excesos de la comunicación. Buenos Aires: Nueva Visión, 2011, P. 64.

THÉMATA. Revista de Filosofía, Nº 49 enero-junio (2014) pp.: 85-103 doi: 10.12795/themata.2014.i49.05 
Hay que tener en cuenta que el poder de la palabra, pero también de la imagen, es la capacidad de retirarla voluntariamente, y que el silencio, como la soledad, ocupan un momento y un lugar imprescindible en cualquier acto comunicativo. ¿Qué consecuencias tendrá para la intimidad no reconocer el espacio de lo indecible? ¿Y para la consistencia del yo el difuminar los límites entre un espacio público y privado, la no existencia de zonas de reserva o secretos ${ }^{13}$ ?

¿Qué sucede cuando adolescentes de comportamiento normal en el entorno familiar y escolar deciden subir a una red social una foto de un compañero durmiendo en una forma que les resulta graciosa, pero que fácilmente es motivo de burla, sin previa consulta al afectado, y sin ningún tipo de interrogante respecto a lo que implica hacer esto? Este es un caso relativamente simple de lo que sucede actualmente en el entorno de muchas redes sociales de público adolescente. El que lo lleva a cabo no es más que un usuario, y quienes consumen la imagen o el comentario son, no más que Usurarios que no sienten la necesidad de preguntarse por las consecuencias de su acción de cara al afectado y de cara a sí mismos, su realidad se limita a ser testigos del hecho de estar presentes ${ }^{14}$. Uno pasa la imagen porque otro se la ha pasado, es una posibilidad que ofrece el móvil, se hace en un instante, es entretenido y parece no implicar un análisis ulterior. La inmediatez con la que todo sucede dificulta un análisis racional.

La cuestión es, entonces, preguntarse hacia dónde deriva la comunicación y con ella la palabra, la imagen, fuera de categorías éticas y de un análisis racional. Castells, más optimista que Le Breton, habla de las virtudes del mundo internet haciendo hincapié, con razón, en la necesidad de la educación para saber qué hacer con la tecnología. Sin embargo, educación puede ser un término tremendamente vago tomado en su generalidad. Cabe preguntarse entonces si los distintos agentes sociales y educativos, incluyendo familia, escuela, medios y grupo de iguales, como agentes por excelencia, presentan una conciencia generalizada de estos riesgos que resultan menos visibles que asuntos más alarmantes como un ciberacoso sexual, que responde a un delito, pero que son potencialmente dañinos, y si están haciendo frente a estos nuevos comportamientos de la forma adecuada. En lo que a la institución escolar se refiere $^{15}$, a veces el interés fundamental está centrado en utilizar estos medios

[13] La violencia al secreto no se ejecuta en realidad por creer decir todo lo que nos pasa sin reservar nada, sino por obviar precisamente con esto que hay cuestiones de nosotros y de otros que no dejan de ser un secreto que desconocemos.

[14] Op. Cit. p. 64.

[15] Apelamos a este caso, porque a pesar de que la escuela ha perdido fuerza y reconocimiento para las nuevas generaciones debido entre otros asuntos al enorme atractivo que presentan los medios, sobre todo, televisión e internet, sigue siendo una institución que junto a la familia cuenta con autoridad y respaldo legal de la sociedad. Véase Fernández Enguita, M. La escuela a examen.

THÉMATA. Revista de Filosofía, No 49 enero-junio (2014) pp.: 85-103

doi: 10.12795/themata.2014.i49.05 
como recurso educativo para trabajar diferentes contenidos, algo que se hace visible en los intereses de numerosos programas de formación del profesorado, pero no queda muy claro si constituye también un recurso con el que educar a la persona, asunto que requeriría un tratamiento más transversal y claramente interdisciplinar, y con la mirada educativa y políticamente puesta, además de en el fracaso escolar y sus motivos, además de en las posibilidades de éxito escolar sin sesgos hacia los que por su origen ya están más favorecidos, además de en estadísticas e informes, también en la formación racional y crítica de los estudiantes. Abundar en cómo se concreta esto último sigue siendo un asunto pendiente en un contexto donde los procesos educativos escolares tienden a estar más centrados en la superación de cursos que en el sentido de lo que se hace en esos cursos, y en una concepción marcadamente consumista de la propia educación, algo que se hace especialmente visible en el caso de los estudios de carácter no obligatorio.

Con esta reflexión no se pretende negar la existencia, ni tan siquiera la necesidad de una comunicación de dimensión más frívola que forma parte natural de las regiones traseras en las que se desenvuelve nuestra vida social. El interés es remarcar que la comunicación convertida en consumo, en actividad que se realiza más desde una motivación técnica que una inquietud humana, y que nos dificulta la diferenciación de espacios, intensidades, o jerarquías en el decir, pierde calado, y hace que lo pierdan el lenguaje, el pensamiento y las relaciones en el seno de la cultura. En este sentido nos hacemos eco de las reflexiones y nuevas fórmulas que los propios magnates de las comunicaciones buscan para conjugar las posibilidades tecnológicas, las tradiciones contemplativas y la sabiduría ${ }^{16}$.

\section{El individuo disponible a tiempo completo}

En este fundamento contemporáneo de la existencia basado en la comunicación, con las derivas que se han presentado anteriormente, reaparece en escena el ideal de un individuo expuesto y dispuesto de manera orgullosa y a tiempo completo a comunicarse. Esta circunstancia nos lleva, por un lado, a profundizar en el sentido de la disponibilidad, y también a reflexionar sobre la dimensión temporal de la existencia y las condiciones de la libertad personal.

Madrid, Pirámide, 2009 Pp. 23-25.

[16] Remitimos al libro de Sherry Turkle Alone Together, obra en la que estudia de manera particular a la población adolescente, pero también la repercusión de la técnica sobre otras generaciones, y plantea las dificultades de tipo emocional y social que manifiestan para expresar emociones, pedir perdón. Las relaciones virtuales denotan una incapacidad para estar solos y generan una percepción de control de las relaciones y de disminución de riesgos que se nos escapan en el cara a cara. La autora afirma que hemos llegado a un punto en el que esperamos más de la tecnología que de las personas.

THÉMATA. Revista de Filosofía, №49 enero-junio (2014) pp.: 85-103 doi: 10.12795/themata.2014.i49.05 
La disponibilidad, más allá de la falacia técnica de que el individuo pueda estar disponible a cualquier hora, para cualquiera y por cualquier pretexto, y convertida con la aparición del teléfono móvil en una caricatura ${ }^{17}$, es una categoría ética. Gabriel Marcel se aproximó a las raíces ontológicas que implicaba este concepto. En primer lugar, la disponibilidad se entiende a partir de la concepción del ser propio, no como un haber o una propiedad, sino como un don, lo que nos lleva a pensar que la disponibilidad excluye el criterio de la mera utilidad o utilización del otro y por supuesto, el control o vigilancia que se puede ejercer sobre otro. Esta concepción de la disponibilidad entra en conflicto con el individualismo actual en su dimensión más egocéntrica. Esto implica que la disponibilidad no puede reducirse a la contestación a un mensaje, sino que comporta una actitud de apertura que se hace desde lo más personal.

"Cuando reflexiono sobre el hecho de que ocupo un determinado lugar en el mundo, cuando me aplico a desnudar lo que recubre mi ecceidad, soy conducido a reconocer que mi condición de viviente hace de mí un ser no solamente sometido, como va de suyo, a determinismos objetivamente reconocibles, sino también expuesto, o si se quiere, abierto a una realidad distinta, con la cual de alguna manera entro en relación (...) ¿Con qué condiciones puedo entrar en comunicación con esta realidad distinta? (...) es necesario que yo pueda hacer sitio en mí de alguna manera al otro; si estoy enteramente absorto en mí mismo, fijo sobre mis sensaciones, sentimientos y preocupaciones, me será manifiestamente imposible captar o incorporarme al mensaje del otro. Lo que hace un momento llamaba incohesión se me presenta aquí como disponibilidad (...) lo positivo de la disponibilidad estaría ya de alguna manera preformado o prefigurado en el seno de la receptividad pura. ¿Qué es, pues, en realidad recibir?»» ${ }^{18}$.

La experiencia del recibir para Marcel no es pasiva, no es un mero padecer, sino que es un modo de acoger lo de fuera. La esencia ontológica del recibir se descubre en que se recibe en lo de uno, en lo propio ${ }^{19}$, y en el fondo se trata de un acto de donación. Para empezar, lo propio es mi cuerpo. Así, pues, recibimos al otro a partir de nuestro ser encarnado, en nuestro espacio, en nuestra casa vital. La invitación que las nuevas tecnologías nos hacen a estar disponibles a tiempo completo, desposeídos del cuerpo, puede suponer una manera de tergiversar el sentido de la disponibilidad porque eluden el compromiso ético que supone el cuerpo y las limitaciones que éste, en cuanto a sus características biológicas, psicológicas y humanas presenta. No descuidamos al respecto que ya se ha generado cierto imperativo social por el que no contestar de inmediato, no estar vigilante a los mensajes que nos llegan, puede ser penalizado por el otro, siendo el otro, un conocido o un superior en el ámbito profesional ${ }^{20}$.

[17] Le Breton: Elogio del caminar. Madrid: Siruela, 2011, P. 19.

[18] Marcel, G.: Filosofía Concreta, Madrid: Revista de Occidente, 1959, p.104. (Las cursivas son del autor).

[19] Marcel destaca a este respecto la importancia que tiene la preposición francesa chez, que indica precisamente relación con un soi (sí), entendiendo por éste el que puede ponerse como moi (yo). Cfr. Op. Cit., pp. 39, 105.

[20] Cfr. Carr, N. Superficiales. ¿Qué está haciendo internet con nuestras mentes? Barcelona: Taurus, 2011.

THÉMATA. Revista de Filosofía, № 49 enero-junio (2014) pp.: 85-103

doi: 10.12795/themata.2014.i49.05 
Esto no significa, como anteriormente se indicó, que sin la presencia del cuerpo se pierda cualquier sentido ético, pero hace más llevadero relacionarnos con el otro desde su categoría de perfil y no de persona, y ante este cambio las exigencias no son las mismas. No hacernos presentes desde nuestro cuerpo y frente al cuerpo del otro permite con cierta ociosidad dar a la tecla de escape cuando no nos interesa o pedir perdón sin enfrentar necesariamente la vergüenza propia

\subsection{La trampa del tiempo como instante}

La falacia de la disponibilidad a tiempo completo trae consigo una experiencia del tiempo ceñida al instante, entendido como la urgencia, la inmediatez, aquello que no puede esperar. Sin embargo aquí hallamos una trampa porque la jerarquía de prioridades necesaria para discernir lo anodino de lo vitalmente importante para el individuo queda anulada en primera instancia por una posibilidad técnica. Vivir el presente no equivale a vivir el instante. El presente no es posible renunciando a la memoria, la imaginación, la voluntad, es durar ${ }^{21}$.

¿Qué es estar disponible? ¿Qué lugar juega el tiempo en la posibilidad real de la disponibilidad? Ceder a un ritmo frenético no es metafísicamente hablando estar más disponible, sino actuar sin capacidad de selección y reflexión y desatender el momento presente. La experiencia de la intensidad del tiempo reside más que en atender de manera frenética muchas actividades o de responder de manera compulsiva todos los reclamos que nos llegan, que tal vez es una forma de acabamiento, en dar sentido a lo que hacemos sin que gobierne tanto en nosotros la política de lo que no hacemos ${ }^{22}$.

La experiencia del presente tiene que ver con la atención. Nuestros procesos atencionales cuentan con un sistema de filtros que permiten seleccionar los estímulos y responder. Las condiciones de vida del mundo actual, que nos exponen a un contexto personal, social y laboral multitarea, provocan a menudo, un colapso en la atención que se experimenta de modo negativo en forma de incapacidad, de urgencia, o lo que es peor, de creer que puedes con todo sin provocarte una herida a ti mismo en la forma de perder de vista el contorno de tus límites. La actividad multitarea dificulta nuestra capacidad de concentración y hace especialmente difícil formas de pensamiento que requieren reflexión y contemplación. Por un lado nos vuelven más eficientes para procesar información, pero nos hace también menos capaces de profundizarla ${ }^{23}$. Cuando

[21] Comte-Sponville, A.: Invitación a la filosofía. Barcelona: Paidós contextos, 2011, p. 137, 138. [22] Gabilondo, A. [en línea] "En blanco", El País (2012) http://blogs.elpais.com/el-salto-delangel/2012/08/en-blanco.html

[23] Cfr. Carr, op. cit.

THÉMATA. Revista de Filosofía, Nº 49 enero-junio (2014) pp.: 85-103 doi: 10.12795/themata.2014.i49.05 
queremos atender muchas cosas, cuando estamos expuestos a una sobrecarga estimular, que se hace patente en los teléfonos móviles, en el acceso a la información disponible en red, etc. nos volvemos despistados ${ }^{24}$, y el despiste es una condición de no vivir el momento.

La urgencia cotidiana del vivir que ha traído consigo el desarrollo económico y tecnológico, principalmente, ha supuesto una experiencia del tiempo a modo de vacío que está por llenar. De tal manera que el ritmo acelerado nos crea la falsa percepción de estar llenando tiempo, haciendo algo con el tiempo y no tener tiempo para nada ${ }^{25}$. El tiempo como categoría objetivable, socialmente establecido, laboralmente organizado, controlado y cosificado en gran medida, pesa sobre nuestras cotidianidades, y el resto, que podríamos etiquetar como tiempo de ocio, que parece ser el tiempo liberado de las obligaciones socio-laborales, que es un tiempo organizado subjetivamente queda cada vez más planificado desde fuera, orientado hacia prácticas de consumo también de orden mediático, que más bien devoran la experiencia del tiempo subjetivo como presente. Cabe interpretar que la posibilidad técnica de la disponibilidad como un estar abocado hacia fuera, ha boicoteado el tomarse tiempo para vivir que requiere de un hacia dentro, de un ejercicio de reflexión.

\subsection{Ser libre en la sobreabundancia de posibilidades}

Otro de los grandes terrenos movedizos en relación con este planteamiento compete a la experiencia de la libertad de la voluntad (aunque la reflexión quizás también sería extrapolable a la libertad política y la de conocer). Existe también una creencia al respecto en virtud de la cual la técnica crea condiciones para la libertad en tanto que configura muchas posibilidades para el individuo en forma de nuevos contactos, acceso a una información sin límites. Tal como describe Bauman esta situación, pareciera que el principio del placer se hubiera reconciliado con el principio de la realidad, lo cual no significa que hayan desaparecido las tensiones, sino simplemente que son diferentes ${ }^{26}$. Sin embargo, además del peligro de la dependencia, las cuasi-infinitas posibilidades que se abren de intercambio, de acceso a información, de imágenes, pueden derivar en una pérdida de la medida humana si el individuo no es capaz de filtrar o seleccionar aquello que puede interiorizar, lo cual supone una acción de la libertad y un acto psicológico de la atención. Ser libre tiene que ver con decidir a qué prestar atención, pero como se ha indicado, la atención se ve afectada por la abundancia y condicionada por las posibles penalizaciones que

[24] Carr indica que la distracción es inherente a las tecnologías.

[25] Al respecto el filósofo español José Ortega y Gasset decía ¿no tienes tiempo para nada o no tienes nada para el tiempo?

[26] Bauman, Z. Mundo Consumo. Barcelona: Paidós. 2010, p. 43.

THÉMATA. Revista de Filosofía, № 49 enero-junio (2014) pp.: 85-103

doi: 10.12795/themata.2014.i49.05 
puede sufrir uno al no estar lo suficientemente vigilante ante la información que le llega. La atención, además, libera importantes batallas competitivas entre empresas e instituciones para ganar consumidores, de manera que captar la atención del consumidor es un valor al alza.

Frente al tumulto estimular de la red la libertad corre el riesgo de quedar anonadada, a pesar de la apariencia de tener el mundo entre las manos. La libertad de autocreación toma conciencia de sí en un contexto donde se abre una oferta cuasi-infinita de posibilidades ${ }^{27}$. Sin embargo, esta apertura muestra también la necesidad de puntos de orientación fiables y nos vuelve vulnerables ante todo tipo de ofertas tras las que se puede encontrar el oportunismo y los intereses privados. Todo aquello que no somos capaces de interiorizar, de hacer nuestro, se purga o se almacena manteniéndonos en un estado de excitación y de distracción ${ }^{28}$. Situaciones como que el interlocutor pueda hacer un seguimiento de tus entradas y salidas, de cuándo abres los mensajes, en el what Sapp, etc. constituye una práctica de vigilancia sobre el otro que crea una vulnerabilidad en el individuo. En un sentido más amplio y también más peligroso, la inmensa base de datos que generamos los millones de usuarios de la red con nuestras informaciones, abre nuevas posibilidades en positivo, pero también crea un espacio para la manipulación y la vigilancia social ${ }^{29}$. Lejos de los usuarios queda el uso que muchas empresas puedan hacer de la información disponible para intentar beneficiarse. Ahora bien, el conocimiento acerca de esta circunstancia ya constituye un instrumento para protegerse frente a esa utilización.

Consideramos que hacer mucho, responder mucho, ver mucho nos hace más libres porque abarcamos más, craso error, porque el ejercicio de la libertad se opera sobre lo concreto, en un acto de conciencia profundo.

Actualmente los referentes son abiertos y casi infinitos. Para bien y para mal, la sociedad red ha supuesto este cambio. Sin embargo, la variedad en esa cantidad escandalosa no significa necesariamente configurar una vida con más criterio, ni por supuesto con más libertad. La superabundancia constituye una amenaza para la libertad porque produce el encandilamiento de la conciencia y lleva a la paralización de la capacidad de interpretar y pensar en nuestros límites, que son lo que nos ofrece todas las posibilidades de ser alguien y no de ser cualquiera. Esto es, de configurar un mundo y no vivir la vida de todo el mundo.

\section{[27] Op. Cit., p. 42.}

[28] Safranski, R. Cuánta globalización podemos soportar?Barcelona: Tusquets, 2004, P. 81.

[29] Al respecto, recientemente y en torno al caso Snowden el periódico The Guardian ha publicado una información según la cual existe una relación económica entre empresas tecnológicas como Google, Yahoo, Microsoft y Facebook con la Agencia Nacional de seguridad estadounidense (NSA).

THÉMATA. Revista de Filosofía, $\mathrm{N}^{\circ} 49$ enero-junio (2014) pp.: 85-103 doi: 10.12795/themata.2014.i49.05 


\section{La medida humana: cuerpo e interioridad}

Todo el análisis anterior nos ha presentado algunos de los riesgos que pesan sobre los individuos actuales. Principalmente se trata de riesgos que suponen una amenaza para lo más propio e íntimo de las personas, afectando a categorías existenciales como la experiencia del tiempo, la libertad de la voluntad, el encuentro con el otro, la relación con uno mismo. Estos riesgos nos sitúan en una posición especialmente vulnerable en dos sentidos. En primer lugar por lo que son en sí mismos, manifestaciones de la fragilidad humana, experiencias también de la ambigüedad de la que aparece revestida la experiencia concreta ${ }^{30}$, y en segundo, porque en un mundo articulado en torno al capitalismo de consumo o capitalismo del ego ${ }^{31}$, el mercadeo de las cuestiones del alma constituye un riesgo añadido. Indudablemente el imperativo de la comunicación ha dado lugar a una deconstrucción de la intimidad tal como la conocíamos hasta hace poco, esto es, como contexto de lo privado. Las nuevas posibilidades y la permanente invitación que se nos hace desde los mass media a narrar la privacidad ha generado un límite difuso entre el espacio público y el privado.

La búsqueda de puntos de orientación, muchas veces puestos en manos de quienes se atreven a ofrecer recetarios fáciles para acceder a la paz interior, a la felicidad, etc. complican aún más la situación. Si lo que demanda la gente es puntos de orientación, eso es lo que produce el mercado $^{32}$. De tal modo que el foco del problema mismo se convierte también, engañosamente en la solución.

¿Cómo situarnos ante este borroso horizonte? ¿Qué posibilidades de acción reales se pueden desplegar frente a estas amenazas? La propuesta que aquí se lleva a cabo es la de la vuelta a lo concreto, la reconquista del territorio personal, de la reflexión. La búsqueda de una medida humana, personal desde la que vivir el mundo, lo que supone el trazar unos límites. Al respecto gozan de una inquietante actualidad las palabras de Goethe:

«El hombre ha nacido en una situación limitada; puede ver determinados fines sencillos, cercanos, y se acostumbra a utilizar los medios que tiene a mano en su entorno; pero tan pronto como se encuentra ante un horizonte más amplio, no sabe ya lo que quiere, ni lo que debe hacer, y es completamente igual que se distraiga por el conjunto

[30] Marcel, G.: En Chemin, vers quel éveil? París: Gallimard, 1971 P. 41, 42

[31] Beck, U. [en línea] "El capitalismo del ego engendra monstruos", El País (2013) http://elpais. com/elpais/2013/02/24/opinion/1361725119_089805.html

[32] Baudrillard señaló que la diferencia entre el capitalismo clásico y el de la sociedad de consumo estriba que en el primero se producen mercancías y en el segundo se produce la demanda misma. La sociedad de consumo. Madrid: Siglo XXI, 2009, estudio introductorio. En el mismo sentido, Lipovetsky, al analizar las diferentes etapas de la sociedad de consumo plantea la última etapa como centrada más que en la oferta en la demanda misma. La felicidad paradójica. Barcelona: Anagrama, 2010.

THÉMATA. Revista de Filosofía, No 49 enero-junio (2014) pp.: 85-103 doi: 10.12795/themata.2014.i49.05 
de los objetos, o que salga de quicio por la altura y dignidad de los mismos. Le abruma la desdicha siempre que se ve incitado a aspirar a algo con lo que no puede unirse mediante una regular actividad propia» ${ }^{33}$.

La primera vía en la reapropiación de lo concreto viene del lado de nuestra dimensión corporal. Gabriel Marcel señaló que el cuerpo era el dato central de la metafísica ${ }^{34}$. Esta escueta afirmación encierra todo el enigma y el misterio que rodea al cuerpo y pone de manifiesto que las cuestiones relativas al sentido, pasan por el cuerpo. Marcel había concebido el existir ligado al hecho corporal, como «que tengo de qué hacerme conocer y reconocer por mí mismo y por los otros, es decir, significa que hay $m i$ cuerpo» $^{35}$. Especialmente destacado fue su estudio de la sensación que permite el reconocimiento de la existencia propia ${ }^{36}$ y constituye la primera forma de participación en el mundo haciendo posible un conocimiento inmediato. Abundando en el sentido de la sensación, Marcel remarcó que se trataba de una experiencia activa, que configura un feedback entre la experiencia del recibir, de lo que el autor, con cierto énfasis denomina el chez soi y la del participar en el mundo. Así pues, el sentir es una experiencia del cuerpo y del mundo, del cuerpo en el mundo y del mundo en el cuerpo.

La relación que guardo con el cuerpo que soy es de intimidad, y en el cuerpo se integran de una manera misteriosa la forma, la expresión, la moral, lo individual y lo social, la naturaleza y la cultura. Por ello, la ocupación del cuerpo no está al margen de la ocupación del alma, y la educación debe estar orientada a la relación estrecha de ambas.

Actualmente, el cuerpo, absorbido también por la maquinaria del consumo ha sido convertido, no ya en objeto, lo que sería fruto de una visión básica del asunto, sino en categoría simbólica por excelencia donde se encarnan las nuevas ideologías contemporáneas ${ }^{37}$. El empeño mediático-consumista por convencernos de nuestro cuerpo puso en alerta a Baudrillard, quien se preguntaba: «El cuerpo, ¿no es acaso la evidencia misma?» ${ }^{38}$. El cuerpo como objeto de culto pone al individuo en una relación conflictiva permanente con su propio cuerpo, en tanto que la aspiración última de su inversión en el cuerpo es la con-

[33] Citado por Safranski en op. cit., pp. 79-80.

[34] Marcel, G. Ser y Tener. Barcelona: Caparrós, 1996, p. 22.

[35] Filosofía Concreta, p. 27. En una línea similar, aunque desde un discurso sociológico, David Le Breton también define la existencia por referencia al cuerpo, a los gestos, a la significación dada a los estímulos que nos rodean, a los ritos corporales. En Sociología del cuerpo, p. 8.

[36] Marcel lleva a cabo una crítica al intento de objetivar la sensación porque se corresponde con una visión instrumental del cuerpo que él rechaza. Cfr. Diario Metafísico, Buenos Aires: Losada, 1957, p. 252. También de convertirla en un proceso pasivo. Cfr. Filosofía Concreta, pp. 38, 39. Él se refiere a una experiencia del sentir que revela nuestro ser en el mundo.

[37] Juventud, belleza, salud, placer.

[38] Baudrillard, J. op. cit., p. 155.

THÉMATA. Revista de Filosofía, №49 enero-junio (2014) pp.: 85-103

doi: 10.12795/themata.2014.i49.05 
quista de una abstracción, de un ideal de cuerpo que penaliza en todo momento el cuerpo real, que es el único con el que contamos. A través de la invitación seductora a una experiencia del cuerpo calculada, programada, incitada, nuestra sensación es objeto de manipulación, y la relación con el cuerpo acaba dejando a un lado esa inmediatez del cuerpo y del mundo que planteara Marcel.

En momentos de especial incertidumbre y convulsión, como los que ahora vivimos, la vuelta al cuerpo, a su cuidado, es una búsqueda de seguridad, de soporte existencial, que abre una vía muy lícita y propicia de vuelta a lo concreto, a lo personal, pero que a la vez nos expone al discurso comercial que, apropiándose ávidamente del cuerpo como modo de ser, y no una mera posesión, nos intenta convencer vía consumo de todo un servicio de atención al cuerpo para vivirlo y sentirlo más en plenitud. Desde el discurso más optimista, el cuerpo es presentado como fuente de experiencias singulares, para lo cual se requiere una inversión en diversas técnicas de cuidado etc., desde el lado más negativo, el cuerpo es un instrumento a corregir gracias a una amalgama de productos, en los que también se requiere una inversión. Ambas son potencialmente experiencias alienantes del cuerpo por cuanto convierten al cuerpo en un instrumento de gran rentabilidad económica.

En la vía lícita, y muy en conexión con la reflexión de Marcel podríamos destacar el trabajo de investigación sobre el cuerpo que lleva realizando desde muchos años el antropólogo y sociólogo David Le Breton. Él ha denunciado la subutilización del cuerpo que tiene lugar en la sociedad contemporánea, y es que hoy día nos resulta más próximo todo lo que nos viene dado a través de los medios que el propio cuerpo, siendo este uno de los motivos que convierten nuestra relación con el cuerpo en un foco de tensión. El carácter superfluo del cuerpo debilita el sentimiento de consistencia del yo, la acción sobre lo real y la experiencia y conocimiento del mundo ${ }^{39}$. La experiencia de los sentidos, al contacto con el mundo, no solo constituye una forma de conocimiento inmediato, (algo que fácilmente se olvida ante el deslumbramiento que nos generan las ciencias y las técnicas, y ante la socialización que la escuela, en conexión con el mundo laboral, lleva a cabo con eficacia, para que pongamos todo nuestro interés en los conocimientos escolares, con un claro sesgo hacia lo racional-instrumental), sino que son una vía para reencontrarnos con nosotros mismos, en tanto que nos descubren nuestro cuerpo. Uno de las grandes desmanes en la experiencia del cuerpo, actualmente, consiste en hacernos creer que sólo lo experimentamos cuando emprendemos acciones grandilocuentes o entramos en contacto con productos de consumo de alto nivel. La experiencia del cuerpo, parece entonces quedar en nada al margen del consumo, y el deseo, domeñado desde cuidadosas campañas de marketing pierde fuerza vital entrando en connivencia con el propio sistema de producción. Al respecto cabe mencionar que

[39] Le Breton, D.: Elogio del caminar. Pp. 16-17.

THÉMATA. Revista de Filosofía, № 49 enero-junio (2014) pp.: 85-103

doi: 10.12795/themata.2014.i49.05 
Nokia ha patentado un tatuaje magnético que vibra cuando el teléfono móvil suena o recibe algún mensaje. En este caso, el cuerpo es un accesorio de la tecnología que consigue paliar su precariedad, pero que incrementa también su valor técnico y de mercancía frente al valor moral ${ }^{40}$.

Tal vez, más que entregarnos al reclamo interesado de experiencias corporales calculadas, deberíamos conceder una atención mayor al cultivo de la sensibilidad que nos permite captar valores morales y estéticos y puede que la posibilidad de un diálogo real entre las personas no sólo tenga que ver con exposición de argumentos, sino también con educación de sensibilidades.

\section{Reflexión y serenidad}

Muy en conexión con la reapropiación del cuerpo se encuentra la llamada a la reflexión. La relación serena y apacible con el cuerpo, que implica la presencia activa del cuerpo a través de los sentidos, de la movilidad, invitan también a la reflexión, que es un pensamiento pausado. Hace ya muchos años, pero curiosamente es una captación extrapolable al momento actual, en una alocución que Heidegger presentó con motivo de la conmemoración del 175 aniversario del compositor Conradin Kreutzer, declaró:

"La falta de pensamiento es un huésped inquietante que en el mundo de hoy entra y sale de todas partes. Porque hoy en día se toma noticia de todo por el camino más rápido y económico y se olvida en el mismo instante con la misma rapidez (...) El hombre se encuentra en una situación peligrosa en esta tierra. ¿Por qué? ¿Sólo porque podría de pronto estallar una tercera guerra mundial que tuviera como consecuencia la aniquilación completa de la humanidad y la destrucción de la tierra? No. La revolución de la técnica (...) puede deslumbrarlo y cegarlo de tal modo, que un día el pensar calculador pudiera llegar a ser el único válido y practicado. ¿Qué peligro se avecinaría entonces? La indiferencia hacia el pensar reflexivo» ${ }^{41}$.

La cultura de la inmediatez y del cambio fulgurante ha asestado un duro golpe al proceso reflexivo que no es buen aliado de las urgencias, sino que se sabe a salvo en la vivencia pausada del tiempo, en la atención centrada, espacios donde se pueden construir argumentos y razones sobre las cosas. Tal vez sea uno de los desafíos del momento el conjugar la rapidez con la que cambian las circunstancias de la vida con la manera de llevar a cabo el ejercicio de la reflexión.

Ortega y Gasset señala tres momentos clave en la construcción de la historia humana y su cultura. El primero de ellos tiene que ver con la apertura. Es lo que el filósofo llama alteración. Se trata del estadio inicial del ser humano en

[40] Este es uno de los paradigmas actuales en torno al cuerpo. David Le Breton habla del cuerpo supernumerario que requiere ser rectificado por la ciencia y la técnica. En Sociología del cuerpo. Buenos Aires, Nueva Visión, 2002.

[41] Heidegger, M.: La Serenidad. Barcelona, Del Serbal, 2002. Pp. 17 y 30

THÉMATA. Revista de Filosofía, Nº49 enero-junio (2014) pp.: 85-103 doi: 10.12795/themata.2014.i49.05 
el mundo, momento en el que está expuesto a un mundo que resulta amenazante $\mathrm{y}$ frente al que hay que garantizar la supervivencia. El segundo momento tiene que ver con la vida contemplativa y la posibilidad de teorizar sobre el mundo, de interiorizar el mundo convirtiéndose en un observador, y esa atención hacia el interior es trabajo de miles de años. Y el tercer momento alude a la vuelta al mundo que se produce tras la contemplación, y que tiene que ver con la acción. En el análisis del ensimismamiento Ortega señalaba como uno de los grandes hitos el desarrollo de la técnica entendida como elemento central de la cultura en tanto que permite la creación de un mundo a medida, humanizado. La relación entre técnica y ensimismamiento es de un feedback muy estrecho, donde es difícil establecer quien precede a quién, porque la capacidad de ensimismarse hace posible la creación de la técnica, pero ésta, a su vez, hace posible la vuelta hacia el interior puesto que el individuo ya no tiene que estar tan pendiente de todas las amenazas que le acechan ${ }^{42}$. Parece que esa relación a la que apuntaba Ortega no es algo obsoleto, sino que la técnica, perdida o ausente la capacidad de reflexión, nos convierte en bárbaros tecnológicos o lo que podríamos considerar también consumidores brutos de tecnología con fines insulsos.

El desarrollo de la capacidad reflexiva nos permite tomar la existencia entre nuestras manos y no ser presas de las circunstancias. Uno de los principales bloqueos o límites a la reflexión del individuo reside en la exposición constante al flujo de información y el hábito generado de vivir expuesto a los mensajes continuos sin mayor afán que estar entretenidos o esquivar algo que nos supone una amenaza interna.

Nos encontramos existencialmente hablando en un momento en el que se requiere una redirección de la atención hacia el interior para protegernos del ruido incesante de la información y para elaborar argumentos que contribuyan a dar consistencia al individuo y también a la sociedad democrática.

Con respecto a la serenidad, cabe remitirse a la reflexión que sobre la misma planteaba Heidegger en su breve disertación relativa al dominio técnico sobre el mundo y el ser humano tomando como referencia la era atómica. En dicho escrito, se aproxima a la serenidad concibiéndola como una actitud de sí y no ante la técnica, lo que se traduce en hacer un uso razonable de la misma ${ }^{43}$. Este posicionamiento sereno del ser humano ante las cosas, que incluyen también las nuevas técnicas que protagonizan el presente, no pensamos que se deba sólo al pensar reflexivo, sino que también implica de lleno nuestra relación con el cuerpo. La relación con el tiempo se teje en el propio cuerpo. No sólo porque el cuerpo, en un sentido biológico nos conduce por una trayectoria temporal conta-

[42] Véase Ensimismamiento y alteración, en Obras completas, Tomo V. Madrid: Alianza, 1994. Meditación de la técnica: Madrid, Santillana, 1997. y posteriormente en El hombre y la gente. Ortega plantea los tres estadios por los que pasa la relación del hombre con la circunstancia: alteración, ensimismamiento y acción.

[43] Heidegger, M. op. cit. p. 28

THÉMATA. Revista de Filosofía, №49 enero-junio (2014) pp.: 85-103 doi: 10.12795/themata.2014.i49.05 
bilizada en años y en el cambio registrado en el proceso de envejecimiento, sino porque el tiempo subjetivo se organiza también corporalmente. La serenidad no tiene que ver sólo con un posicionamiento intermedio, comedido, sino con la experiencia misma del tiempo en nuestro modo de vivir en el cuerpo. La relación con el cuerpo propio, y con el cuerpo ajeno es compleja, la vida es un proceso en el que nunca terminamos de incorporarnos a nuestro cuerpo. La serenidad y la urgencia, se registran en el cuerpo: respiración, movimientos, gestos, emociones, etc. y la propia relación con el cuerpo nos vuelve serenos o ansiosos.

\section{Conclusión}

Como cierre a este trabajo, pero no como clausura de lo que en él se plantea, retomamos el posicionamiento esgrimido a lo largo de sus partes consistente en dejar claro que no se ha intentado defender ningún tipo de conservadurismo cultural, sino que más bien se ha pretendido una actitud de estar al acecho.

Esta actitud nos ha llevado a tropezar con paradojas que rodean nuestra vida actual centrada en nuevas posibilidades de comunicación gracias al desarrollo tecnológico, y hemos podido comprobar cómo algunos de los autores que han profundizado el tema aportan argumentos más positivos y menos al respecto. Esta confrontación es interpretada en positivo ya que vislumbra la riqueza y complejidad cultural en la que nos encontramos. Asimismo, al exponer estas paradojas y riesgos se ha podido dar cuenta de la dimensión interdisciplinar que se requiere para abordar toda esta problemática, aunque en este trabajo han predominado más los argumentos de tipo filosófico o sociológico. Esta limitación en el trabajo presente abre, no obstante, la puerta a un trabajo de carácter interdisciplinar, algo que Edgar Morin manifiesta imprescindible para abordar lo complejo.

Como trasfondo en todo el artículo late una cuestión antropológica renovada a la luz de los nuevos cambios o más bien del proceso de aceleración del cambio al que estamos asistiendo, cambio que ha alcanzado un ritmo intrageneracional $^{44}$, y que se presenta como nuestra circunstancia. También se despliega una cuestión de orden metafísico, ya que el consumo de la comunicación nos sitúa en un mercado-mundo al que subyace con ímpetu una búsqueda de puntos de orientación y sentido.

Por último manifestar, haciéndonos eco de unas palabras de Manuel Cruz, que el intento y esfuerzo por entender las incongruencias, contradicciones y paradojas en las que andamos envueltos es "uno de los mejores legados que les podemos dejar a las generaciones futuras ${ }^{45}$ ", entre otras cosas, porque la vida transita por ellas.

Vivir requiere el riesgo de pensar, comunicarse requiere el riesgo de vivir y por tanto de pensar.

[44] Fernánez Enguita, M.: op. cit., pp. 238-239.

[45] Cruz, M. [en línea] “Amar la duda” El País (2010) http://elpais.com/diario/2010/10/26/opinion/1288044004_850215.html

THÉMATA. Revista de Filosofía, Nº 49 enero-junio (2014) pp.: 85-103

doi: 10.12795/themata.2014.i49.05 


\section{Referencias bibliográficas:}

Baudrillard, J. La sociedad de consumo. Madrid: Siglo XXI, 2009.

Bauman, Z. Mundo consumo. Barcelona: Paidós, 2010.

Beck, U. [en línea] "El capitalismo del ego engendra monstruos", El País (2013)

http://elpais.com/elpais/2013/02/24/opinion/1361725119_089805.html

Breton, P., Le Breton, D. El silencio y la palabra frente a los excesos de la comunicación. Buenos Aires: Nueva Visión, 2011.

Carr, N. Superficiales. ¿Qué está haciendo internet con nuestras mentes? Barcelona: Taurus, 2011

Castells, M. [en línea] "Internet y la Sociedad Red" (2001) http://www.uoc.edu/ web/cat/articles/castells/castellsmain2.html

Castells M. Subirats, M. Hombres y mujeres, ¿un amor imposible? Madrid: Alianza, 2007.

Comte-Sponville, A. Invitación a la filosofía. Barcelona: Paidós contextos, 2011. Cruz, M. [en línea] "Amar la duda" El País (2010) http://elpais.com/diario/2010/10/26/opinion/1288044004_850215.html

Feito, R. (coord.) Sociología de la educación secundaria. Barcelona: Graó, 2010 Fernández Enguita. La escuela a examen. Madrid: Pirámide, 2009.

Gabilondo, A. [en línea] "En blanco", El País (2012) http://blogs.elpais.com/elsalto-del-angel/2012/08/en-blanco.html

Heidegger, M. La Serenidad. Barcelona: Del Serbal, 2002.

Houellebecq, M. Las partículas elementales. Barcelona: Anagrama, 2002.

IAB y ELOGIA [en línea] "IV Estudio anual de redes sociales". (2013) http:// www.iabspain.net/wp-content/uploads/downloads/2013/01/IV-estudio-anualRRSS_reducida.pdf

Le Breton, D. Sociología del cuerpo. Nuevos Aires: Nueva visión, 2002

Elogio del caminar. Madrid: Siruela, 2011

Lipovetsky, G.: La felicidad paradójica. Barcelona: Anagrama, 2010

- La cultura mundo. Barcelona: Anagrama, 2012.

Marcel, G. Diario Metafísico. Buenos Aires: Losada, 1957.

-Filosofía Concreta. Madrid: Revista de Occidente, 1959.

-Ser y tener. Barcelona: Caparrós, 1996

-En chemin, vers quel éveil? París: Gallimard, 1971.

Ortega y Gasset, J. Ensimismamiento y alteración, en Obras completas, Tomo V. Madrid: Alianza, 1994.

Safranski, R. ¿Cuánta globalización podemos soportar? Barcelona: Tusquets, 2004.

Verdú, V. Tú y yo objetos de lujo. Barcelona: Debolsillo, 2005

THÉMATA. Revista de Filosofía, $\mathrm{N}^{\circ} 49$ enero-junio (2014) pp.: 85-103

doi: 10.12795/themata.2014.i49.05 
